\title{
ESTAQUIA EM ANONAS 1
}

\author{
ERIVALDO JOSÉ SCALOPPI JUNIOR ${ }^{2} \&$ ANTONIO BALDO GERALDO MARTINS ${ }^{3}$
}

RESUMO-Annonaceae é uma importante família de plantas constituintes da flora nacional com espécies produtoras de frutos para consumo in natura, medicinal e para diversos fins. O objetivo do artigo é apresentar informações disponíveis na literatura sobre a propagação vegetativa por estaquia de algumas espécies de Annonaceae com potencial para consumo in natura e como porta-enxerto, principalmente. Conclui-se que a literatura apresenta resultados de enraizamento variados, mesmo dentro de espécie. O sucesso do enraizamento de estacas é dependente de fatores como espécie, variedade, planta-matriz, época do ano, reguladores vegetais, ambiente de enraizamento e juvenilidade. Algumas espécies de Annonaceae apresentam potencial para a propagação por estacas, porém a literatura é escassa de trabalhos referentes à formação de muda e condução de plantio. A utilização de reguladores vegetais exógenos favorece o enraizamento na maioria das espécies com potencial para a propagação por estacas.

Termos para indexação: Annonaceae, Annona spp., Rollinia spp., propagação vegetativa, multiplicação assexuada.

\section{ANONAS CUTTING}

ABSTRACT - Annonaceae is an important family of plants that constitutes the Brazilian flora. Anona species produce fruits for fresh consumption, medicinal use and other purposes. The aim of this study is to present information of literature about vegetative propagation by cutting of some Annonaceae species with potential for consumption and as rootstock. As conclusion, the literature presents a range of rooting results, even about the same species. The rooting success depends on the species, variety, stock plant, season, plant growth regulators, rooting environment and juvenility. Some species present rooting potential, but there are lack of literature about plant management and orchard installation. The use of plant growth regulators improves the rooting of the most species with potential to propagate by cuttings.

Index terms: Annonaceae, Annona spp., Rollinia spp., vegetative propagation, asexual reproduction.

\section{INTRODUÇÃO}

A família Annonaceae é importante tanto evolutiva, ecológica como economicamente. Em número de espécies, Annonaceae é de longe a mais sobressalente dentro da ordem das Magnoliales, as quais se encontram entre as angiospermas mais primitivas. Geralmente, estão distribuídas entre as áreas tropicais da América, África e Ásia. A família abriga cerca de 2.500 espécies em 140 gêneros tropicais (Chatrou, 1999, citado por PINTO et al., 2005).

No Brasil, a família Annonaceae compreende 26 gêneros e aproximadamente 260 espécies, desempenhando um importante papel na composição da vegetação (MAAS et al., 2006). Para consumo in natura, o País cultiva, principalmente, a fruta- do-conde ou pinha (A. squamosa) e a atemoia ( $A$. cherimola x A. squamosa), híbrido interespecífico entre a cherimólia e a fruta-do-conde. Em relação ao processamento, apenas a graviola (A. muricata L.) é explorada com a finalidade de obtenção de polpa.

A maioria das espécies dessa família é considerada subutilizada, e a informação sobre elas é escassa e amplamente dispersa. Todavia, as áreas sob produção têm crescido mais rapidamente do que a contribuição da ciência e tecnologia (PINTO et al., 2005).

As anonáceas destacam-se entre outras fruteiras devido ao seu sabor bastante agradável, a respeito de ser a cherimólia (Annona cherimola Mill.) considerada uma das três frutas mais saborosas do mundo, junto com o mangustão e o abacaxi (DONADIO et al., 1998).

\footnotetext{
${ }^{1}$ Palestra Anonáceas - V Congresso Internacional \& Encontro Brasileiro sobre Annonaceae: do gene à exportação ( 19 a 23 de Agosto de 2013). Botucatu-SP.

${ }^{2}$ Pesquisador Científico, Dr., IAC/APTA, Centro de Seringueira e Sistemas Agroflorestais. Rodovia SP 461, km 121 (+ $6 \mathrm{~km}$ terra), CP 61, CEP 15500-970, Votuporanga-SP. E-mail: scaloppijr@yahoo.com.br

${ }^{3}$ Prof. Dr., UNESP/FCAV, Departamento de Produção Vegetal. Via de acesso Prof. Paulo Donato Castellane s/n, CEP 14.884-900, Jaboticabal-SP. E-mail: baldo@fcav.unesp.br
} 
Em relação à forma de propagação, Camargo e Kavati (1996) consideram que a formação de mudas, possibilitando a obtenção de pomares de anonáceas homogêneos, produtivos e com frutos de qualidade elevada, precisa evitar o uso da propagação sexuada em qualquer de suas fases. Portanto, a obtenção de porta-enxertos ou de mudas da cultivar copa via assexuada, mediante estacas, propicia a fixação das características desejáveis de uma planta-matriz, necessárias na formação de um pomar de Annonaceae competitivo, além da redução do tempo de formação da muda (HARTMANN et al., 1997).

Existe variação considerável entre cultivares de pés-francos de cherimólia, sendo a fruta-do-conde e a graviola conhecidas como menos variáveis (GEORGE; NISSEN, 1987; PINTO; SILVA, 1996), não justificando, porém, o uso da propagação sexuada na instalação em plantios, como é feito por produtores comerciais no Brasil (PINTO; RAMOS, 1999).

A produção de porta-enxertos por semente proporciona grandes diferenças na performance individual entre árvores, com a produção variando muito mais de $100 \%$. É possível o aumento da produção com a utilização de clones superiores de porta-enxertos (SANEWSKI, 1988).

Já que as anonáceas são consideradas espécies alógamas, com alta heterogeneidade, e não produzem, geralmente, plantas idênticas ao parental, os pomares comerciais deveriam ser propagados por clonagem para evitar possíveis influências da variabilidade genética.

As espécies de Annonaceae mais exploradas apresentam em maior ou menor grau, problemas, quando da tentativa de propagação vegetativa, sendo sua propagação sexual de escasso valor agronômico, devido ao alto grau de heterozigose das espécies, o que desaconselha sua propagação por sementes (ENCINA et al., 1999).

A eficiência da estaquia não é satisfatória em algumas espécies de Annonaceae, havendo necessidade de incremento no enraizamento.

O método de propagação por estaquia pode ser influenciado por diversos fatores, dentre os quais, as características inerentes à própria planta e às condições do meio ambiente. Dentre os fatores que podem melhorar os resultados, destacam-se a presença de folhas na estaca, utilização de câmara com nebulização intermitente, reguladores de crescimento, estádio de desenvolvimento da plantamatriz e do próprio ramo, além da época do ano em que as estacas são coletadas. A juvenilidade, período em que a planta se apresenta incapaz de florescer e produzir, é uma característica importante na propagação via estaquia, pois plantas neste estádio, em sua maioria, apresentam maior capacidade de enraizamento, pela maior emissão de raízes adventícias (HARTMANN et al., 1997; KOMISSAROV, 1968).

O objetivo deste trabalho é apresentar informações disponíveis na literatura sobre a propagação por estaquia de algumas espécies de Annonaceae.

\section{Annona cherimola Mill.}

Nome comum em português: cherimólia; nome comum em inglês: cherimoya.

Duarte et al. (1974) observaram o efeito da juvenilidade em estacas de um ano em cherimólia. Estacas lenhosas enfolhadas foram coletadas a intervalos mensais e tratadas com $0 ; 1.250 ; 2.500$ e $5.000 \mathrm{mgL}^{-1}$ de ácido naftaleno acético (NAA) Nenhuma das estacas retiradas das plantas adultas enraizou. Algumas estacas retiradas de plantas com um ano de idade enraizaram de 20 a $25 \%$ com $5.000 \mathrm{mgL}^{-1}$ de NAA.

Tentativas de propagação em cherimólia com estacas tratadas com várias combinações de benzilamino purina (BAP) e ácido indolbutírico (IBA) não tiveram sucesso após quatro meses, embora algumas produzissem poucas raízes (GEORGE; NISSEN, 1987).

Em cherimóia a capacidade morfogenética é muito reduzida, sobretudo em nível de enraizamento, implicando, na propagação vegetativa por métodos clássicos, uma ineficácia e inviabilidade comercial, já que é quase impossível a indução de raízes adventícias em estacas obtidas de espécies adultas com interesse agronômico (ENCINA et al., 1999).

Em um estudo preliminar com estacas de cherimólia, George e Nissen (1987) verificaram que o estiolamento pode proporcionar bons resultados. Os custos adicionais envolvidos na produção de plantas por este método podem ser compensados por altas produções e resistência às doenças das plantas clonais. Todavia, até a data do trabalho, nenhum método comercialmente viável para propagação vegetativa por estaquia existia em cherimólia.

Na Itália, Tazzari et al. (1990) obtiveram sucesso no enraizamento de estacas herbáceas em algumas variedades de cherimólia, alcançando $39 \%$, enquanto outras não apresentaram resultado satisfatório, mostrando a dependência da variedade utilizada no sucesso da propagação por estaquia. 
Annona cherimola Mill. x Annona squamosa L.

Nome comum: atemoia.

Em atemoia, existe intenso ataque da broca do coleto, além da incidência de doenças nas raízes. A muda tipo 'produtor direto' (estaca enraizada da variedade copa) pode ser utilizada em locais onde não existam esses problemas (TOKUNAGA, 2000).

A propagação por estacas apicais tem sido descrita para a atemoia com sucesso, quando na presença de folhas, ao contrário das estacas sem folhas (GEORGE; NISSEN, 1987; HARTMANN et al., 1997).

Ferreira e Cereda (1999) obtiveram como melhor resultado em atemoia $27 \%$ de enraizamento utilizando Rootone ${ }^{\circledR}$ e $25 \%$ com a testemunha. Conforme os autores, são resultados altos, em se tratando de estacas de difícil enraizamento.

Incrementos na produção de atemoia cv. African Pride (18,7 t/ha) e cherimólia (9,2 t/ha) foram obtidos quando da propagação por estacas. O florescimento, a qualidade de frutos e os dois ciclos de colheita por ano foram superiores quando comparados com a produção e o desenvolvimento de plantas provenientes de semente (GEORGE; NISSEN, 1986).

Sucessos de 60 a $80 \%$ são comumente reportados em atemoia cv. African Pride. Estacas de outras variedades como 'Pink's Mammoth' e a cherimólia têm demonstrado dificuldade em enraizar, com médias inferiores a 20\% (SANEWSKI, 1988).

Costa Júnior et al. (1998) utilizaram o IBA em estacas semilenhosas de atemoia cv. Pink, nas concentrações de 0 (testemunha), 1.000, 2.000 e $4.000 \mathrm{mgL}^{-1}$ e obtiveram um enraizamento de $6 ; 7 ; 11 ; 15,5$ e $40 \%$, respectivamente. Além de proporcionar o maior enraizamento, a concentração de $4000 \mathrm{mgL}^{-1}$ promoveu um maior número de raízes por estaca.

Uma técnica de alporquia modificada em atemoia foi usada por George e Nissen (1986) com $100 \%$ de pegamento. Plantas jovens com um ano de idade foram cortadas rente ao solo em meados do verão e produziram de 3 a 5 ramos juvenis. Quando os ramos atingiram $15 \mathrm{~cm}$, anéis constritores metálicos foram colocados sobre cada ramo, então cobertos com plástico e substrato (areia e serragem), deixando apenas os pontos de crescimento expostos. Excelente sistema radicular foi produzido após 4 a 5 meses.

Estacas de atemoia cv. Gefner, Bradley e PR-3 tratadas com IBA nas concentrações de $1.000,2.000$ e $3.000 \mathrm{mg} \mathrm{L}^{-1}$, durante 5 segundos, apresentaram, respectivamente, 36; 60 e 50\% de enraizamento. $\mathrm{O}$ regulador vegetal utilizado não promoveu aumento na percentagem de enraizamento (SAVAZAKI, 2000).

Scaloppi Júnior (2007) conduziu, por dois anos, experimento com estacas apicais e medianas de atemoia 'Gefner' tratadas com IBA em ampla faixa de concentração ( 0 a $7.000 \mathrm{mgL}^{-1}$ ) via tratamento rápido, por 5 segundos em solução alcoólica. Como resultados, as estacas apicais não reagiram à aplicação de IBA, com resultados médios de $38 \%$ de enraizamento. Nas estacas medianas, a aplicação de $3.000 \mathrm{mgL}^{-1}$ IBA possibilitou obter, na média, 36\% de enraizamento. Portanto, em estacas medianas, deve-se aplicar IBA exógeno para incrementar os resultados em relação à testemunha. Aproximadamente $60 \%$ das mudas feitas tiveram origem das estacas subapicais (medianas), que apresentaram maior sobrevivência, provavelmente pela maior reserva energética nos tecidos.

Ferreira et al. (2008) utilizaram os reguladores vegetais IBA e NAA aplicados na forma de talco em três tipos de estacas (apical, mediana e basal) de atemoia 'Gefner'. O maior potencial para formação de mudas foi verificado com o emprego de estacas apicais sem tratamento ( $80 \%$ de enraizamento) e medianas tratadas com $0,5 \%$ NAA (68 \% de enraizamento).

Ferreira e Ferrari (2010) realizaram experimento com estacas de atemoieira cv. 'Gefner' utilizando IBA, NAA e 2,4-D, durante 24 horas (tratamento lento), nas concentrações $0 ; 50 ; 100 ; 200$; 300; 400 e $500 \mathrm{mg} \mathrm{L}^{-1}$ de cada regulador e durante 5 segundos (tratamento rápido) nas concentrações 0 , 500; 1.000; 2.000; 3.000; 4.000 e $5.000 \mathrm{mg} \mathrm{L}^{-1}$ de cada regulador. Os autores concluíram que o tratamento lento, com $200 \mathrm{mg} \mathrm{L}^{-1}$ de NAA, proporcionou incremento ao processo, da mesma forma que o tratamento rápido com IBA, independentemente da concentração. Os índices de enraizamento obtidos foram superiores a $90 \%$.

\section{Annona crassiflora Mart.} marolo.

Nome comum em português: araticum,

Bianco e Pitelli (1981) realizaram experimento com estacas apicais, medianas e basais de marolo sem a utilização de reguladores vegetais. Os resultados foram insatisfatórios, não havendo indícios de enraizamento. Em ensaio posterior, os autores utilizaram IBA e NAA nas concentrações de 0; 50 e 100 ppm e Rootone ${ }^{\circledR}$ em estacas medianas e basais. Não houve enraizamento em qualquer tratamento. Ocorreu intensa brotação das gemas apicais das estacas retiradas da parte mediana e basal dos ramos. Os autores atribuem o não enraizamento 
à falta de material de reserva nas estacas, pelo fato de ocorrer brotação das gemas apicais e não basais. Também, Carvalho (2002) considera o insucesso no enraizamento do araticum explicado pelas poucas reservas nutritivas de suas estacas.

\section{Annona glabra L.}

Sinonímia botânica: Annona palustris L.; Annona chrysocarpa Small.; Annona klainni Pierre ex Engler \& Diels (LORENZI et al., 2006).

Nome comum em português: anona-do-brejo, anona-lisa; nome comum em inglês: pond apple.

Ocorre em toda a América tropical e no Brasil, com ampla distribuição geográfica. É encontrada desde a Amazônia até o Estado de Santa Catarina (BRAGA, 1976). Nos locais de ocorrência natural, ocupa frequentemente áreas que estão submetidas a inundações periódicas (PAULA; ALVES, 1997). Pinto e Silva (1996) descreveram a planta e os frutos.

É considerada como um porta-enxerto ananizante, conferindo pequeno porte às plantas indicadas para áreas úmidas, por tolerar podridões radiculares. Devido a estas características, está sendo usada em um programa de melhoramento para a obtenção de porta-enxertos superiores (PINTO et al., 2005).

Quando da utilização desta espécie como porta-enxerto para graviola, além de conferir porte baixo à copa, demonstra boa compatibilidade e facilita o manejo da cultura (FERREIRA et al., 1987; PINTO; SILVA, 1996; PINTO; GENÚ, 1984; SÃO JOSÉ et al., 2000).

O enraizamento de $A$. glabra no período de verão foi de $94 \%$, ante os valores observados no outono e inverno, que decresceram para $20 \%$ e $4 \%$, respectivamente, sendo que não houve diferenças entre testemunha e as diferentes concentrações do regulador utilizado (IBA), via tratamento rápido (SCALOPPI JÚNIOR; MARTINS, 2003).

\section{Annona montana Macfad.}

Nome comum em português: falsa-graviola, anona-das-montanhas, araticum-apé; nome comum em espanhol: guanábana cimarrón; nome comum em inglês: mountain soursop, wild soursop.

Planta nativa das Índias Ocidentais, que se assemelha muito à graviola. A descrição da planta e frutos é encontrada em Benza (1993). A espécie é recomendada como porta-enxerto para a gravioleira (PINTO; GENÚ, 1984; FERREIRA et al., 1987; SÃO JOSÉ et al., 2000).

A estaquia da $A$. montana realizada no período de verão, outono e inverno proporcionou resultados de enraizamento médios de $48 \%, 8 \%$ e $14 \%$, respectivamente, independentemente da concentração de IBA utilizada (SCALOPPI JÚNIOR; MARTINS, 2003).

\section{Annona muricata L.}

Nome comum em português: graviola; nome comum em inglês: soursop.

Em um estudo com estacas enfolhadas de graviola (Annona muricata L.) tratadas com diversos reguladores vegetais, não foi obtido nenhum enraizamento (CASAS et al., 1984).

Em Porto Rico, foram obtidos $20 \%$ de enraizamento em graviola, utilizando solução de $50 \mathrm{ppm}$ IBA em etanol a $50 \%$, sob luz difusa e nebulizador. Em outro experimento, estacas de graviola foram deixadas em água durante 12 a 24 horas, em concentrações de 0,01 a $0,03 \%$ dos antibióticos matromicina, ABT-6778 ou terramicina, antes do tratamento por imersão em IBA. Entre 70 e $80 \%$ das estacas tratadas com os antibióticos e regulador enraizaram. Aquelas tratadas somente com IBA enraizaram apenas de 30 a 40\% (MANICA et al., 2003).

Santos et al. (2011) utilizaram estacas apicais tenras com $12 \mathrm{~cm}$ de comprimento e com duas ou quatro folhas, mantidas inteiras, pela metade ou com $1 / 4$ do tamanho original, provenientes de plantas-matrizes com oito anos de graviola 'Gigantede- Alagoas'. Todas as estacas foram tratadas com $2.000 \mathrm{mgL}^{-1}$ IBA. Estacas com duas folhas cortadas apresentaram enraizamento próximo a $70 \%$. O menor número e o tamanho das folhas nas estacas promoveram a porcentagem de enraizamento e o número de raízes.

Estacas de graviola não produzem raiz pivotante e, como resultado, são suscetíveis aos ventos fortes (SCUC, 2006).

\section{Annona squamosa $\mathrm{L}$.}

Nome comum em português: pinha, fruta-doconde; nome comum em inglês: sugar apple.

Bourke (1976) avaliou a propagação de fruta-do-conde por estacas e obteve sucesso em menos de $5 \%$.

Bankar (1989) obteve, como melhor resultado em A. squamosa, $26 \%$ de enraizamento com IBA (2.500-3.000 $\left.\mathrm{mgL}^{-1}\right)$, demonstrando a necessidade do uso de reguladores vegetais, pelo fato de a testemunha ter apresentado somente $4 \%$ de enraizamento.

No enraizamento de estacas semilenhosas de pinha, graviola e atemoia, contendo 2 pares de folhas, Marinho e Lemos (1996) obtiveram o máximo de $18 \%$ no tratamento com $2.000 \mathrm{mgL}^{-1} \mathrm{IBA}$, independentemente das espécies utilizadas. Estacas que apresentaram, pelo menos, uma folha original 
emitiram raízes.

Silva (2008) concluiu que a propagação por estaquia de pinha, graviola e atemoia é viável, principalmente no verão, e que o uso das auxinas IBA e NAA na forma de talco (pó) contribui para as porcentagens de enraizamento, sobrevivência e calosidade das estacas, e número e comprimento das raízes. Para a pinha, foi obtido até $38 \%$ de enraizamento utilizando $0,5 \%$ IBA ou $0,75 \%$ NAA. Para a graviola, observou-se até 37\% de enraizamento, no tratamento com $0,75 \%$ IBA. Para a atemoia, o enraizamento de $35 \%$ foi verificado nas estacas tratadas com $0,25 \%$ IBA e $0,75 \%$ IBA. O autor também concluiu que o uso do bioestimulante

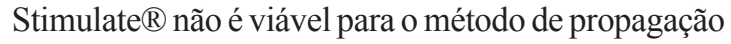
por estaquia.

\section{Rollinia sp.}

Nome comum: araticum-de-terra-fria.

$\mathrm{O}$ araticum-de-terra-fria foi utilizado pela primeira vez como porta-enxerto de atemoia pelo agricultor Pedro Costa, de São Bento do Sapucaí (SP), que entendeu tratar-se de Rollinia emarginata, pois Rollinia sp. é conhecida nessa região como araticum-mirim. Descobriu-se, dessa forma, um novo e eficiente porta-enxerto. A descrição da planta, frutos, área de abrangência e demais características é encontrada em Tokunaga (2000).

$\mathrm{O}$ araticum-de-terra-fria possui tolerância às podridões de raízes, à broca do tronco e boa compatibilidade de enxertia em atemoia e cherimólia. Da semeadura à enxertia levam-se aproximadamente 18 meses (BONAVENTURE, 1999).

Bettiol Neto et al. (2006) verificaram 56\% de enraizamento para o araticum-de-terra-fria com a utilização de $3.000 \mathrm{mgL}^{-1}$ IBA.

Blat et al. (2002) conduziram um experimento com duas cultivares de atemoia (Gefner e Thompsom) enxertadas sobre araticum-mirim (Rollinia emarginata) e araticum-de-terra-fria propagados por semente e por estaca. As estacas foram obtidas por meio de tratamento com IBA 1.000 mg L ${ }^{-1}$ diluído em talco, segundo recomendação de Mitra e Bose (1996) e colocadas para enraizar em substrato artificial (50\% de areia grossa e 50\% de vermiculita grossa), sob nebulização intermitente. Os autores concluíram que o desenvolvimento inicial das plantas enxertadas sobre araticum-de-terra-fria é mais vigoroso do que as plantas enxertadas em araticum-mirim. Não houve diferenças no vigor das plantas, enxertadas sobre porta-enxertos, obtidos por semeadura ou estaquia. Os autores obtiveram enraizamento de $50 \%$ em R.emarginata e $60 \%$ para
Rollinia sp. O pegamento da enxertia das duas copas nos diferentes porta-enxertos foi de $100 \%$.

Estacas de araticum-de-terra-fria oriundas de plantas-matrizes adultas e de plantas jovens com dois anos foram submetidas ao tratamento lento (12 horas) com IBA, nas concentrações de 0, 100, 200 e $400 \mathrm{mgL}^{-1}$ em associação com o elemento mineral boro $\left(0 ; 50 ; 100\right.$ e $\left.150 \mathrm{mgL}^{-1}\right)$, resultando na combinação de 16 tratamentos para cada material (matriz jovem e adulta). Observou-se 25\% de enraizamento nas estacas provenientes de matrizes jovens e enraizamento nulo nas estacas de matrizes adultas (SCALOPPI JÚNIOR, 2007).

Diante dos resultados encontrados, há a necessidade de se verificar o potencial de enraizamento em diferentes fenótipos, pois Rollinia sp. possui ampla distribuição geográfica, sendo possível a seleção de variedades (TOKUNAGA, 2000).

\section{Rollinia emarginata}

Sinonímia botânica: Rollinia glaucescens; Rollinia hassleriana var. vestita R.E. Fr.; Rollinia intermedia R.E. Fr.; Rollinia occidentalis R.E. Fr. (LORENZI et al., 2006).

Nome comum: araticum-mirim, araticum-dobrejo, araticum-de-folha-miúda.

Nos anos de 1960, o viveirista Salvador Iori, de Tremenbé (SP), produzia mudas de atemoia utilizando Rollinia emarginata como porta-enxerto, contribuindo muito para a difusão da cultura da atemoia. $\mathrm{O}$ araticum-mirim induz o ananismo sobre a copa. É indicada para solos de várzea, mas adaptase bem em solos de encosta. O início da produção é antecipado em um ano quando comparada com plantas enxertadas sobre atemoias, cherimólias ou Rollinia sp. (TOKUNAGA, 2000).

$\mathrm{O}$ araticum-mirim possui tolerância satisfatória às podridões de raízes, boa tolerância à broca do tronco (Cratosomus bombina) e boa compatibilidade de enxertia em atemoia e cherimólia. Apresenta desenvolvimento inicial lento, levando cerca de 30 meses antes de poder enxertar, quando propagado por sementes. O enxerto sobre esta espécie resulta em produção mais precoce, com excelente sistema radicular, além de resistência a solos úmidos, podendo sobreviver em terrenos alagáveis (BONAVENTURE, 1999).

Em experimento conduzido com estacas de araticum-mirim de plantas-matrizes adultas propagadas durante o verão, outono e inverno, observaram-se porcentagens de enraizamento de 19; 15 e $6 \%$, respectivamente, independentemente da concentração de IBA utilizada em tratamento rápido, 
segundo Scaloppi Júnior e Martins (2003).

Estacas de araticum-mirim com um par de folhas e $15 \mathrm{~cm}$ de comprimento tratadas com IBA a 0, 1000, 2000 e $3000 \mathrm{mg} \mathrm{L}^{-1}$ IBA não apresentaram emissão de raízes em quaisquer tratamentos, em experimento conduzido por Bettiol Neto et al. (2006).

Três experimentos com estaquia de araticummirim foram realizados por Scaloppi Junior (2007) com plantas matrizes e ambientes diferentes. O primeiro foi conduzido na UNESP de Jaboticabal utilizando estacas de matrizes adultas oriundas do próprio Campus. O segundo ensaio, na UNESP de Botucatu e terceiro ensaio, no IB/UNESP, Botucatu (câmara de nebulização intermitente com controle de temperatura), utilizaram estacas de matrizes localizadas no Núcleo de Produção de Mudas de Tietê, CATI, SAA. Em cada ensaio foram aplicados 16 tratamentos, resultado da combinação de tratamento lento (12 horas) com IBA nas concentrações de $0,100,200$ e $400 \mathrm{mgL}^{-1}$ em associação com o elemento mineral boro $(0,50$, 100 e $\left.150 \mathrm{mgL}^{-1}\right)$. Na avaliação final do primeiro ensaio, verificou-se enraizamento nulo e $10 \%$ de sobrevivência. No segundo ensaio contatou-se enraizamento nulo e 3\% de sobrevivência. No terceiro ensaio, $60 \%$ das estacas sobreviveram e $20 \%$ enraizaram no tratamento com $100 \mathrm{mgL}^{-1}$ IBA associado com $50 \mathrm{mgL}^{-1}$ de boro. Pode-se concluir que o sucesso do enraizamento em Rollinia emarginata é dependente da presença de folhas nas estacas. A sobrevivência e conseqüente enraizamento das estacas tiveram grande influência do sistema de nebulização, combinado pela freqüência de aspersão e tamanho das gotas na manutenção da umidade relativa, proporcionado no ambiente do terceiro experimento.

\section{Rollinia mucosa (Jacq.) Baill.}

Sinonímia botânica: Annona mucosa Jacq.; A. reticulata var. mucosa (Jacq.) Willd.; Rollinia biflora Ruiz \& Pav. Ex G. Don; R. orthopetala A. DC.; R. deliciosa Saff.; $R$. jimenezii; $R$. mucosa var. macropoda (LORENZI et al., 2006). A descrição da planta é encontrada em Lorenzi (2002).

Nome comum em português: biribá; nome comum em espanhol: biribá, corosoe, anón cimarrón; nome comum em inglês: wild sweet sop.

Seus frutos são de aceitação popular, sendo em sua maioria utilizados no consumo caseiro e comercialização regional (CALZAVARA, 1980). O biribazeiro possui compatibilidade comprovada, quando da enxertia com gravioleira, apresentando resistência às podridões de raízes (JUNQUEIRA et al., 1996). Espécie recomendada como porta-enxerto para a gravioleira (PINTO e GENÚ, 1984; SÃO JOSÉ et al., 2000).

Scaloppi Junior e Martins (2003) observaram necrose de tecido na base das estacas de $R$. mucosa, com resultados de enraizamento não satisfatórios, independente da concentração de IBA utilizada. No experimento, realizado em diferentes épocas do ano, os valores médios de enraizamento encontrados foram de $7 \%, 2 \%$ e $2 \%$, respectivamente para o verão, outono e inverno.

Em estudo feito com estacas de material adulto, Scaloppi Junior et al. (2006) verificaram que o biribazeiro não apresenta camadas de impedimento que venham a dificultar ou interromper o caminhamento ao exterior e a emissão das raízes.

Scaloppi Junior (2007) estudou o efeito da juvenilidade no enraizamento de biribá, com a utilização de estacas provenientes de plantas com um ano, dois anos e plantas matrizes adultas. Em estacas de plantas com um ano houve $40 \%$ de sucesso no enraizamento, sendo que aquelas oriundas de plantas com dois anos e as estacas originadas de plantas adultas não enraizaram. $\mathrm{O}$ índice de enraizamento obtido é considerado satisfatório para plantas difíceis de enraizar.

\section{Rollinia sylvatica (St. Hil) Mart.}

Nome comum: araticum-do-campo, araticumdo-mato, araticum.

Lorenzi (1992) e Tokunaga (2000) descreveram a planta, frutos, áreas de abrangência e demais características. Quando utilizada como portaenxerto para atemóia, apresenta bom pegamento e desenvolvimento inicial, mas ocorre a morte após o transplantio (TOKUNAGA, 2000), devendo, portanto, ser testada em outras espécies.

Dois experimentos de estaquia de Rollinia sylvatica foram realizados por Scaloppi Junior (2007), ambos utilizando plantas matrizes adultas. No primeiro, as estacas foram tratadas com IBA em imersão rápida por cinco segundos nas concentrações de $0,1000,3000,5000$ e $7000 \mathrm{mgL}^{-1}$. No segundo experimento, utilizou-se IBA via imersão lenta por 12 horas nas concentrações de $0,50,100,200$ e 400 $\mathrm{mgL}^{-1}$. Como resultados, no primeiro ensaio, não houve efeito dos tratamentos e o enraizamento médio obtido foi de $6 \%$. No segundo ensaio, realizado no ano posterior, porém na mesma época do ensaio anterior e utilizando as mesmas matrizes, observouse sobrevivência muito baixa e enraizamento de apenas $1 \%$. É intrigante o fato de algumas estacas apresentarem enraizamento satisfatório, com raízes em quantidade suficiente para garantir a perpetuação da espécie, enquanto a grande maioria fracassa e nem 
ao menos sobrevive.

As plantas, com relação ao enraizamento, podem ser divididas em três classes, segundo Hartmann et al. (1997): a) aquelas nas quais os tecidos têm todas as substâncias endógenas, inclusive as auxinas, essenciais à iniciação radicular. São plantas cujas estacas enraízam facilmente; b) aquelas em que os cofatores estão presentes em amplas concentrações, sendo a auxina limitante. Estas são as plantas cujas estacas enraízam com a aplicação de auxinas exógenas; c) aquelas em que falta a atividade de um ou mais cofatores, embora apresentem ou não abundante auxina exógena. Estacas de plantas nestas condições não respondem ou respondem muito pouco à aplicações de auxinas.

\section{Rollinia rugulosa Schl.}

Nome comum: araticum-de-porco.

Rollinia rugulosa é uma árvore nativa de até $12 \mathrm{~m}$ de altura e $40 \mathrm{~cm}$ de diâmetro, nativa no Brasil (desde Minas Gerais até o Rio Grande do Sul), Argentina, Bolívia, Paraguai e Peru (REITZ et al., 1983; ZÁCHIA,1994).

Pinto et al. (2003) submeteram os tratamentos com IBA $\left(2.000,4.000\right.$ e $\left.6.000 \mathrm{mgL}^{-1}\right), \mathrm{NAA}(2.000$, 4.000 e $\left.6.000 \mathrm{mgL}^{-1}\right)$, IBA + NAA $\left(2.000 \mathrm{mgL}^{-1}\right)$ e NAA $5.000 \mathrm{mgL}^{-1}$ (Raizon $05^{\circledR}$ ) em estacas de R. rugulosa coletadas nas quatro estações do ano. Estacas coletadas no outono e no inverno não enraizaram. O máximo de enraizamento (4\%) foi obtido nos tratamentos com IBA $6.000 \mathrm{mgL}^{-1} \mathrm{e}$ IBA + NAA (2.000 $\left.\mathrm{mLL}^{-1}\right)$, na primavera, indicando que $R$. rugulosa apresenta um baixíssimo potencial de enraizamento nas épocas e condições testadas. Verificaram-se $34 ; 67 ; 83$ e $35 \%$ de mortalidade de estacas, respectivamente, na primavera, verão, outono e inverno. A elevada mortalidade no outono, provavelmente, deveu-se à condição fisiológica das estacas.

\section{CONCLUSÕES}

1-A literatura sobre propagação vegetativa por estaquia em Annonaceae apresenta resultados de enraizamento variados, mesmo dentro de espécie.

2-O sucesso do enraizamento de estacas em Annonaceae é dependente de fatores como espécie, variedade, planta-matriz, época do ano, reguladores vegetais, ambiente de enraizamento e juvenilidade.

3-Algumas espécies de Annonaceae apresentam potencial para a propagação por estacas, porém a literatura é escassa de trabalhos referentes à formação de muda e condução de plantio.

4-A utilização de reguladores vegetais exógenos favorece o enraizamento na maioria das espécies com potencial para a propagação por estacas.

\section{REFERÊNCIAS}

BANKAR, G.J. Vegetative propagation in annonas (Annona squamosa L.). Haryana Journal of Horticultural Sciences, Haryana, v.18, n.1-2, p. 10-13, 1989.

BENZA, J.C. 143 frutales nativos. Lima: Universidad Nacional Agrária La Molina, 1993. 366p.

BETTIOL NETO, J. E.; PIO, R.; BUENO, S. C. S.; BASTOS, D.C.; SCARPARE FILHO, J. A. Enraizamento de estacas dos porta-enxertos araticum-de-terra-fria (Rollinia sp.) e araticummirim (Rollinia emarginata Schtdl.) para anonáceas. Ciência e Agrotecnologia, Lavras, v. 30, p.1.0771.082, 2006.

BIANCO, S.; PITELLI, R.A. Estudo da propagação vegetativa de nove espécies de frutíferas nativas comestíveis. Ilha Solteira: UNESP, 1981. p. 110-111. 1981. (Relatório Técnico-Científico, 1).

BLAT, S. F.; BUENO, S. C. S.; SCARPARE FILHO, J. A.; MEDEIROS, F. D. Desempenho de cultivares de atemoia enxertadas sobre duas espécies do gênero Rollinia, propagadas por semente e por estaca. In: CONGRESSO BRASILEIRO DE FRUTICULTURA, 17., 2002, Belém. Anais... Belém: Embrapa, 2002. CD-ROM.

BONAVENTURE, L. El cultivo de la chirimoya y de su híbrido atemoya en Brasil. In: VAN DAMME, V.; VAN DAMME, P.; SCHELDEMAN, X. Procedings of the first International Symposium on Cherimoya. Acta Horticulturae, Wagenigen, n.497, p. 147-151, 1999.

BOURKE, D.O'.D. Annona spp. In: The Propagation of tropical fruit trees. GARNER, R.J.; CHAUDHRI, S.A. (Ed). Horticultural review n.4. Kent: Commonwealth Bureau of Horticulture and Plantation Crops, 1976. p. 223-248.

BRAGA, R. Plantas do Nordeste, especialmente do Ceará. 3.ed. Mossoró: ESAM, 1976. 540p.

CALZAVARA, B.B.G. Fruteiras: abieiro, abricozeiro, bacurizeiro, biribazeiro, cupuaçuzeiro. Brasília: IPEAN, EMBRAPA - CPATU, 1980. 77p. (Série Culturas da Amazônia). 
CAMARGO, C.M.M.S.; KAVATI, R. Observações preliminares sobre o desenvolvimento vegetativo da fruta-do-conde (Annona squamosa L.) sobre diferentes porta-enxertos. In: CONGRESSO BRASILEIRO DE FRUTICULTURA, 14., 1996, Curitiba. Resumos... Londrina: IAPAR, 1996. p.225.

CARVAlho, J. A. Araticum: o doce aroma do cerrado. Belo Horizonte: Gráfica Editora Folha Machadense, 2002. 20 p.

CASAS, M.H.; VICTÓRIA, S.M.A.; ZARATE, R.R.D. Preliminary trials on sexual and assexual propagation of soursop (Annonna muricata L.). Acta Agronomica, Palmira, v.4, p.66-81, 1984.

COSTA JÚNIOR, W.H.; SCARPARE FILHO, J.A; KLUGE, R.A. Enraizamento de estacas semilenhosas de atemoia cv. Pink tratadas com ácido indolbutírico. In: CONGRESSO BRASILEIRO DE FRUTICULTURA, 15., 1998, Poços de Caldas. Resumos... Lavras: UFLA, 1998. p.103.

DONADIO, L.C.; NACHTIGAL, J.C.; SACRAMENTO, C.K. Frutas exóticas. Jaboticabal: Funep, 1998. p.214-215.

DUARTE, O.; VILLAGARCIA, J.; FRANCIOSI, R. Efecto de algunos tratamientos em la propagación del chirimoyo por semillas, estacas e injertos. Proceedings of the Tropical Region of American Society Horticulture Science, Mayaguez, 1974. v.18, p. 41-48.

ENCINA, C.L.; PADILLA, I.M.G.; CAZORLA, J.M.; RUIZ-CAMACHO, N.; CARO, E. Cultivo de tejidos en cherimoya. Acta Horticulturae, Wageningen, n.497, p.295-301, 1999.

FERREIRA, G.; CEREDA, E. Efeito da interação entre fitorreguladores, substratos e tipos de estacas no enraizamento de atemoia (Annona cherimola Mill x A. squamosa L.). Revista Brasileira de Fruticultura, Jaboticabal, v.21, n.1, p.79-83, 1999.

FERREIRA, G.; FERRARI, T. B. Enraizamento de estacas de atemoieira (Annona cherimola Mill. x A. squamosa L.) cv. Gefner submetidas a tratamento lento e rápido com auxinas. Ciência e Agrotecnologia, Lavras, v. 34, p. 329-336, 2010.
FERREIRA, G.; FERRARI, T. B.; PINHO, S. Z.; SAVAZAKI, E. T. Enraizamento de estacas de atemoieira 'Gefner' tratadas com auxinas. Revista Brasileira de Fruticultura, Lavras, v. 30, p. 1.0831.088, 2008.

FERREIRA, S.A.N.; CLEMENT, C.R.; MARTEL, J.H.I. Avaliação de diferentes porta-enxertos para gravioleira na Amazônia central. I. Métodos de enxertia. In: CONGRESSO BRASILEIRO DE FRUTICUlTURA, 9., 1987, Campinas. Anais... Campinas: Sociedade Brasileira de Fruticultura, 1987. v.2, p.475-479.

GEORGE, A.P.; NISSEN, R.J. Custard apple. Biennial Report Maroochy Horticulture Research Station, Queensland, v.4, p.46-68, 1986.

GEORGE, A.P.; NISSEN, R.J. Propagation of Annona species: a review. Scientia Horticulturae, Wageningen, v. 33, p.75-85, 1987.

HARTMANN, H.T.; KESTER, D.E.; DAVIES JUNIOR, F.T.; GENEVE, R.L. Plant propagation: principles and practices. 6 ed. New Jersey: PrenticeHall, 1997. 770 p.

JUNQUEIRA, N.T.V.; CUNHA, M.M.; OLIVEIRA, M.A.S.; PINTO, A.C.Q. Graviola para exportação: aspectos fitossanitários. Brasília: EMBRAPA-SPI, 1996. 67p. (FRUPEX Publicação técnica, 22).

KOMISSAROV, D.A. Biological basics for the propagation of wood plants by cuttings. Jerusalem: IPST Press, 1968. 250p.

LORENZI, H. Árvores brasileiras: manual de identificação e cultivo de plantas arbóreas nativas do Brasil. Nova Odessa: Instituto Plantarum, 2002. v2., p.31.

LORENZI, H.; BACHER, L.; LACERDA, M.; SARTORI, S. Frutas brasileiras e exóticas cultivadas (de consumo in natura). São Paulo: Instituto Plantarum de Estudos da Flora, 2006. 640p.

MAAS, P.J.M.; KAMER, H.M.; JUNIKKA, L.; SILVA, R.M.; RAINER, H. Annonnaceae from Centraleastern Brazil. Disponível em: $<$ http://www.jbrj.gov.br/ publica/rodriguesia/Rodrig52_80/6-maas.pdf $>$. Acesso em: 25 set. 2006. 
MANICA, I.; ICUMA, I. M.; JUNQUEIRA, K. P.; OLIVEIRA, M. A. S.; CUNHA, M. M.; OLIVEIRA JÚNIOR, M. E.; JUNQUEIRA, N. T. V.; ALVES, R. T. Frutas Anonáceas: ata ou pinha, atemoia, cherimólia e graviola: tecnologia de produção, póscolheita e mercado. Porto Alegre: Cinco Continentes, 2003. 596 p.

MARINHO, A.G.; LEMOS, P.E.E. Efeito da aplicação de auxinas no enraizamento de estacas adultas de pinha (Annona squamosa L.), graviola (Annona muricata L) e atemoia (Annona cherimola L. X Annona squamosa L.). In: CONGRESSO BRASILEIRO DE INICIAÇÃO CIENTÍFICA EM CIÊNCIAS AGRÁRIAS, 10., 1996. Fortaleza. Anais... Fortaleza: UFC, 1996. p.134.

MITRA, S. K.; BOSE, T.K. Standardization of propagation techniques by cutting of some tropical fruit crops. Scientific Horticulture, Kent, v.5, p.17.1996.

PAULA, J.E.; ALVES, J.L.H. Madeiras nativas: anatomia, dendrologia, dendrometria, produção e uso. Brasília: Empresa Gráfica Gutenberg, 1997. $543 p$.

PINTO, A.C.Q.; GENÚ, P.J.C. Contribuição ao estudo técnico-científico da graviola (Annona muricata L.). In: CONGRESSO BRASILEIRO DE FRUTICUlTURA, 7., 1983, Florianópolis. Anais... Florianópolis:SBF/EMPASC, 1984. v.2, p.529-546.

PINTO, A.C.Q.; CORDEIRO, M.C.R.; ANDRADE, S.R.M.; FERREIRA, F.R.; FILGUEIRAS, H.A.C.; ALVES, R.E. Annona species. 2005. Disponível em: <http://www.icuc-iwmi.org/files/R7187 _Annona\%20monograph\%202005.pdf $>$. Acesso em: 28 abr. 2006.

PINTO, A.C.Q.; RAMOS, V.H.V. Polinização artificial da graviola. Brasíli: Embrapa Cerrados, 1999. (Guia técnico do produtor rural, 20).

PINTO, A.C.Q.; SILVA, E.M. Graviola para exportação, aspectos técnicos da produção. Brasília: Embrapa/SPI, 1996. 41p.
PINTO, L.S.; ZUFFELLATO-RIBAS, K.C.; CARPANEZZI, A.A.; TAVARES, F.R.; KOEHLER, H.S. Indução do enraizamento de estacas de araticumde-porco pela aplicação de fitorreguladores. Scientia Agraria, v.4, n.1-2, p.41-45, 2003. Disponível em: $<$ http://calvados.c3sl.ufpr.br/ojs2/index.php/agraria/ article/viewPDFInterstitial/1064/886 $>$ Acesso em: 03 jul. 2006.

REITZ, P. R.; KLEIN, R. M.; REIS, A. Projeto Madeira do Rio Grande do Sul. Sellowia, Itajaí, v. 34-35, p. 1-525, 1983.

SANEWSKI, G.M. Growing Custard Apples. Brisbane : Queensland Department of Primary industries, 1988.

SANTOS, M.Q.C.; LEMOS, E.E.P.; SALVADOR, T.L.; REZENDE, L.P.; LIMA SALVADOR, T.; SILVA, J.W.; BARROS, P.G.; CAMPOS, R.S. Rooting soft cuttings of soursop (Annona muricata) 'GIANT OF ALAGOAS'. Acta Horticulturae, Wageningen, v. 923, p. 241-245, 2011.

SÃO JOSÉ, A.R.; ANGEL, D.N.; REBOUÇAS, T.N.H.; SOUZA, I.V.B.; BONFIM, M.P. Cultivo de graviola. Vitória da Conquista: DFZ/UESB, 2000. 27 p.

SAVAZAKI, E.T. Efeito do Ácido Indolbutírico no enraizamento de estacas de três cultivares de atemoia (Annona squamosa L.x Annona cherimola Mill.) e formação da muda. 2000. 30f. Dissertação (Mestrado) - Faculdade de Ciências Agronômicas, Universidade Estadual Paulista, Botucatu, 2000.

SCALOPPI JÚNIOR, E.J. Propagação de espécies de Annonaceae com estacas caulinares. 2007, 87f. Tese (Doutorado em Produção Vegetal) - Faculdade de Ciências Agrárias e Veterinárias, Universidade Estadual Paulista, Jaboticabal, 2007.

SCALOPPI JÚNIOR, E.J.; MARTINS, A.B.G. Clonagem de quatro espécies de Annonaceae potenciais como porta-enxertos. Revista Brasileira de Fruticultura, Jaboticabal, v.25, n.2, p.283-289, 2003. 
SCALOPPI JÚNIOR, E.J.; MARTINS, A.B.G.; SANTOS, J.M. Aspectos histológicos em anonáceas através da microscopia eletrônica de varredura e implicação no enraizamento. In: CONGRESSO BRASILEIRO DE FRUTICULTURA, 19., 2006, Cabo Frio. Resumos... Cabo Frio: SBF/UENF/ UFRRJ, 2006. p.335.

SCUC. Annona: Annona cherimola, A. muricata, A. reticulata, A. senegalensis and A. squamosa, field manual for extension workers and farmers. Southampton: University of Southampton, 2006. 41 p. Disponível em: <http://www.cropsforthefuture. org/publication/Manuals/Annona $\% 20$ extension $\% 20$ manual.pdf $>$. Acesso em: 28 nov. 2012.

SILVA, C. P. DA. Enraizamento de estacas de pinheira (Annona squamosa L.), gravioleira (Annona muricata L.) e atemoeira (Annona squamosa L. x Annona cherimola L.) tratadas com ácido indolbutírico (IBA), ácido naftalenoacético (NAA) e bioestimulante. 2008. 140 f. Tese (Doutorado) - Faculdade de Ciências Agronômicas, Universidade Estadual Paulista, Botucatu, 2008.
TAZZARI, L.; PESTELLI, P.; FIORINO, P.; PARRI, G. Propagation techniques for Annona cherimola Mill. Acta Horticulturae, Wageningen, n.275, p.315-21, 1990 .

TOKUnAGA, T. A cultura da Atemóia. Campinas: CATI, 2000. 80p. (Boletim Técnico, 233).

ZÁCHIA, R. A. Estudos taxonômicos na família Annonaceae Juss. no Rio Grande do Sul. 1994. 366 f. Dissertação (Mestrado em Botânica) - Instituto de Biociências, Universidade Federal do Rio Grande do Sul, Porto Alegre, 1994. 